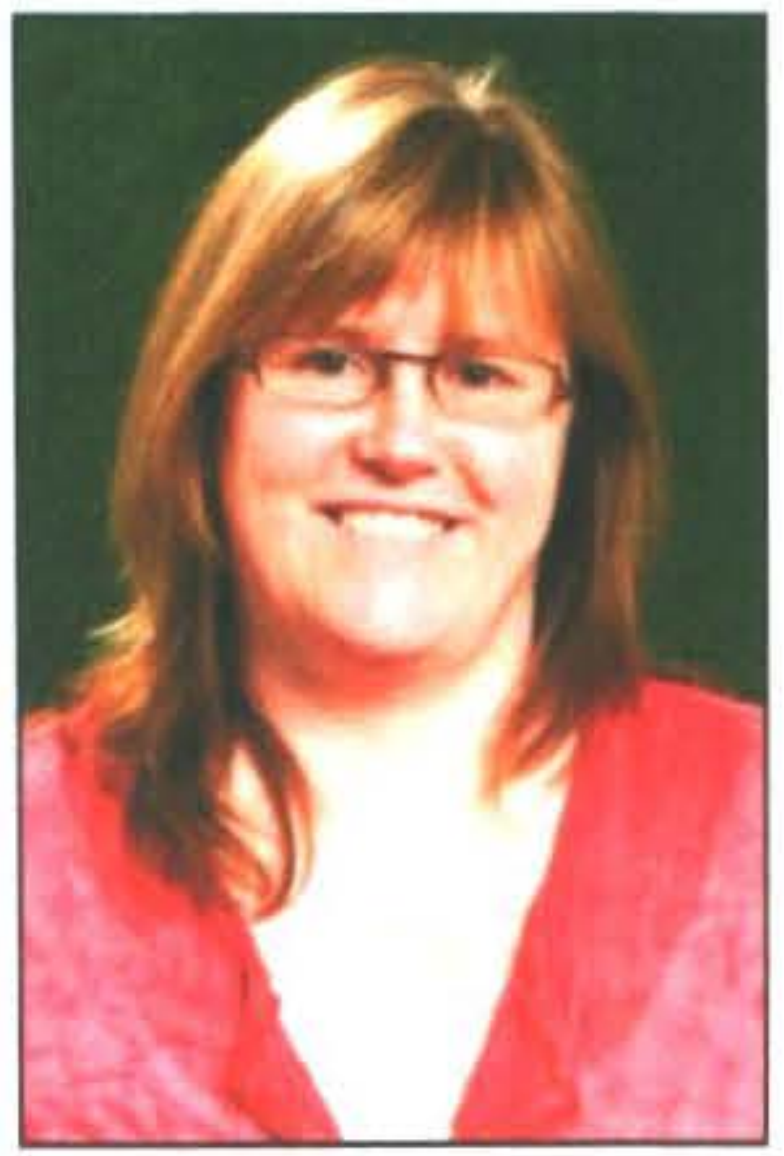

\title{
WORK PATTERNS AFTER \\ PAID PARENTAL LEAVE
}

\author{
Sarah Crichton
}

Department of Labour

\begin{abstract}
This paper uses longitudinal data from the Linked Employer-Employee Dataset to describe the employment and earnings patterns of people who first received paid parental leave between 1 July 2002 and 30 June 2005. Recipients were observed for at least 36 months before starting leave and at least 18 months afterwards. We focused on whether and when recipients returned to work, whether recipients returned to the same employer or not, and changes in earnings before and after taking leave. We also explored associations between prior earnings, the likelihood of returning to work, experiencing a change in earnings, and starting a new employment relationship. We found that 40 percent of recipients were working six months after starting parental leave, and nearly 70 percent were working 1318 months later. Overall three-quarters of recipients returned to work within 12 months of starting parental leave, and two-thirds of those returned to work after taking six months leave or less. Many people reduced their earnings after returning to work. with around one-third earning considerably less than before. Most people who returned to worked within 12 months of starting leave returned to the same employer, while one-fifth started a new employment relationship. Those who did not return to the same employer, but started a new job, were much more likely to have reduced their earnings. While the majority of recipients who returned to work changed their working arrangements, most commonly by reducing their earnings, or in some cases starting a new job, around one-fifth were working for the same employer and had similar earnings 12-18 months after starting parental leave.
\end{abstract}

\section{Introduction ${ }^{1}$}

Maternity leave was introduced in New Zealand in 1981 and provided job protection to eligible mothers, but no period of paid leave. In July 2002, paid parental leave (PPL) was introduced, and employees who had worked continuously for the same employer for at least 12 months became entitled to 12 weeks paid parental leave.

This paper uses longitudinal data from the Linked Employer-Employee Dataset to provide new insights into the employment and earnings patterns of people who first received paid parental leave between 1 July 2002 and 30 June 2005. Recipients are observed for at least 36 months before starting leave, and at least 18 months afterwards. The paper examines whether and when recipients returned to work, whether they returned to the same employer or not, and changes in earnings before and after taking leave. It also explores associations between prior earnings, the likelihood of returning to work, experiencing a change in earnings, and starting a new employment relationship.

While the paper describes employment and earnings in some detail, it does not attempt to explain why some people decide to return to work following a period of paid parental leave and others do not. Personal circumstances, the ability to find suitable child care, the flexibility of working arrangements offered by their employer, and financial incentives to work all influence the decision whether and when to return to work. Unfortunately, information about these aspects is not available from LEED.

\section{Parental Leave in New Zealand}

The Maternity Leave and Employment Protection Act of 1980 introduced maternity leave to New Zealand in 1981. The legislation prescribed minimum maternity leave requirements and protected the rights of female employees during both pregnancy and maternity leave. This was superseded by the Parental Leave and Employment Protection Act 1987 which extended the right to leave to male employees, extended the eligibility criteria (by reducing the service requirement and increasing the duration of leave.) Additional provisions added in 1987 related to the sharing of leave between a male and female partner in order to care for a child. Over time, the legislation has been amended to reflect the growing diversity of family structures and now includes same-sex and de facto relationships. 
The Parental Leave and Employment Protection Amendment Acts of 2002 introduced paid parental leave to New Zealand in July 2002. As well as encouraging greater female workforce attachment and gender equity in the labour market and within families, the introduction of paid parental leave aimed to support families by providing income replacement, supporting the health and wellbeing of new mothers and families, and improving New Zealand's compliance with international human rights instruments that provide for paid maternity leave.

To be eligible for the 12 weeks of PPL employees must have worked continuously with the same employer for an average of 10 hours per week (including one hour in every week or 40 hours in every month) in the 12 months before the baby's expected due date or the date the employee assumes the care of a child they intend to adopt. $^{2}$ Employees can return to work within the 12week paid parental leave period; however, entitlement to paid parental leave ceases at that point.

Employees who were eligible for PPL were also entitled to up to 52 weeks of employment-protected parental leave (less any PPL taken). PPL starts when parental leave starts. Leave can start up to six weeks before the expected date of birth or adoption, or earlier in certain cases. Each type of leave must be taken in one continuous period. Parental leave can be shared between parents where they are both eligible. Eligibility for PPL is primarily determined through the mother. However, if their spouse or partner meets the eligibility criteria the mother can transfer part or all of the leave to them. Employees were required to apply for paid parental leave before they return to work or resign.

In December 2004, PPL was increased to 14 weeks and the eligibility criteria were extended to employees who had six months or more continuous service with the same employer. Those with less than 12 months continuous service were not entitled to further (unpaid) employmentprotected leave. In July 2006, entitlement to PPL was extended to the self-employed. Since its inception, the level of payment has been capped at 50 percent of the average weekly earnings. In 2005 , this was $\$ 347$ per week. Over 90 percent of recipients received the maximum payment over the period 2002-2005.

Considerable changes have occurred in fertility rates, age of child-bearing, women's educational attainment, and participation in paid-work since maternity leave was introduced in 1981. At the same time, working arrangements have become more varied and flexible work arrangements more common. Today, most women work at some stage before having children, and many work afterwards. However, it is still relatively common for women with young children to withdraw from the labour market for some time. This withdrawal is particularly common after the birth of a second or subsequent child. The total number of live births in New Zealand over July 2002-June 2005 was between 55,000 and 58,000 a year, and between 18,000 and 20,000 employees accessed PPL each year. So, only a minority of women who had a child over this period were eligible and received PPL. During this time, women who were self-employed and employees who did not meet the 12month tenure were not eligible for PPL. In the year to 30 June 2008, approximately 26,300 people received PPL, including about 1,800 who were self-employed, while there were 64,100 live births.

In 2005, the Department of Labour undertook an evaluation of parental leave in New Zealand. It examined the eligibility, take-up and return to work patterns of women who had a child between March and May 2005. ${ }^{3}$ It also examined women's preferences for taking leave and factors which influenced decisions about whether and when to return to work. The research included a survey of 501 mothers who had been in paid work at some stage during the six months before having a baby. It included 333 mothers who had accessed PPL. Interviews were conducted 14-17 months after the birth. The research found that PPL enabled eligible mothers to extend the total amount of leave taken. Many women returned to work about six months after giving birth, but most women would have liked to have taken more unpaid leave. About 80 percent of those who had received PPL had returned to work at some stage by the time they were interviewed; two-thirds were working part-time after the birth compared with one-third before the birth; and two-thirds of those who had returned to work went back to the same employer

\section{Data Description}

This study uses data from Statistics New Zealand's Linked Employer-Employee Dataset (LEED) covering the period April 1999 - December 2006. ${ }^{4}$ LEED uses information from tax and statistical sources to construct a record of paid jobs. Each month all New Zealand employers file an Employer Monthly Schedule (EMS) record with Inland Revenue (IRD), which lists all employees at that firm in the month, the amount of income they received, and the amount of tax that was deducted at source. As well as employment earnings, LEED captures and identifies various sources of nonemployment income; specifically, working-age welfare benefits, New Zealand Superannuation, earnings-related accident compensation income, paid parental leave payments, and student allowances.

Employees are identified by a unique confidentialised identifier derived from their IRD tax numbers. In the EMS data, employers are identified by an employer-IRD tax number. This number is an administrative unit to which the EMS return relates, and does not equate to any consistent conception of a firm. We used a version of the LEED data that has allocated EMS returns to geographic units and enterprises as defined in the Longitudinal Business Frame (Seyb, 2003). In this paper, we used LEED data on employers aggregated to the enterprise level. 
Most income data in LEED has a calendar-month reference period due to the way the tax system operates. Employers are required to provide information to Inland Revenue on the tax numbers of their employees and their earnings each calendar month. There is no information on hours worked. When jobs begin or end during a calendar month, the exact start or finish dates are not usually reported, which means it is not possible to tell exactly which individuals were employed on any given day during the month. In this paper, an individual is considered to be 'employed' in any calendar month in which they received any employee earnings.

Throughout our analysis we express earnings and incomes in constant, March 2007 quarter dollar values, adjusted using the Consumers Price Index.

\section{Study Population}

We began by selecting everyone who received PPL between July 2002 and June 2005. We used LEED data up to December 2006, which meant we had an 18-month follow-up period for those who began PPL in June 2005, and a longer period for those who took leave before that.

In December 2004, changes to the eligibility criteria meant that employees were only required to have six months continuous service with the same employer (reduced from 12 months previously). Those with less than 12 months continuous service were not entitled to the further unpaid employment-protected leave. We used the total population in our analysis and did not distinguish between those who received PPL before and after the policy change. However, we estimated that 1.0 percent of our study population became eligible under the new policy (that is, they worked for more than 6 months but less than 12 months before beginning leave, and started parental leave after November 2004). Therefore, nearly all our study population were entitled to 12 months employment-protected leave.

In LEED, 49,550 people first received PPL between July 2002 and June 2005. Of these, 47.510 (96 percent) had one episode of PPL. 2,030 had two episodes, and fewer than 10 people had three episodes of PPL. In total, there were 51,600 episodes of PPL in LEED over the threeyear study period. In this study, we considered individuals first episode of PPL, which will comprise a mixture of first and subsequent births. Inland Revenue (IRD) generates information on the numbers of applications approved, including the numbers of firsttime applications approved. From July 2003 to June 2004. there were about 17,000 applications approved, with 16.600 of these first-time applicants. In LEED, we observed 16,120 first-time recipients during the same period. Differences are expected, due to the approval date preceding payments observed in LEED.

Recipients are required to apply for PPL before they return to work or resign. The start date of paid parental leave coincides with the start date of parental leave, and payments are backdated to the date parental leave started. In LEED, we observed a small number of people (less than 0.1 percent) who started receiving PPL more than six months after finishing work (that is, received some earnings from employment). In 93 percent of cases, the first month of PPL coincided with the last month worked or the following month, and in around 5 percent of cases there is a gap of one month between working and receiving PPL. In cases were PPL was paid out near the time leave began, recipients typically receive PPL payments over a 3- or 4-month period. In most cases where PPL was paid out more than two months after leave began, recipients received a lump sum payment in a single month in LEED.

We observed a small number of PPL recipients who did not appear to have received income from wages and salary during the months immediately before receiving PPL. ${ }^{5}$ Firstly, we restricted the study population to those who received income from wages and salary at some stage during the 12 months immediately before receiving PPL. In most cases where PPL was claimed more than two months after leave began, recipients received a lump sum PPL payment in a single month in LEED. In a small number of cases, there was a gap of more than three months between finishing work and receiving paid parental leave in LEED, and PPL was received over a period of 2-5 months. We also excluded these people from the final study population. There were 230 people who received PPL, but received no income from wages and salary in LEED in the previous 12 months, and a further 110 people had a gap of more than three months between finishing work and receiving paid parental leave in LEED, but received PPL over a period of 2-5 months. We also excluded 60 cases where a first spell of PPL which lasted more than one month was followed by a second spell, and the start of these spells were separated by fewer than nine months. The final study population comprised 49,150 individuals who first received PPL between July 2002 and June 2005.

We did not impose the eligibility criteria of 12 months continuous service (or six months after December 2004) in our sample selection, although we observed that 94 percent of the study population received income from wages and salary in each of the 12 months before beginning leave, and 98 percent of recipients receive income from wages and salary in each of the six months before beginning leave.

We were interested in describing recipients' employment patterns after beginning parental leave, including how quickly recipients return to work, and whether they return to work within the 12 -month income-protected leave period. We treated the first month after the last month employed to be the start of the parental leave period. This means that all people in the study population are employed in the month immediately before the parental leave period starting. Note that individuals may have taken other paid leave before 
beginning parental leave; for example, annual leave or sick leave.

In about 12 percent of cases, people received wage and salary income in a single month during the 12 months following the start of parental leave. These single-month employment spells were either followed by a return to work some months later or by no further earnings over the 12-month period. Single-month employment spells which were followed by at least two months of no earnings during the 12 months following the start of parental leave were not included in our calculation of employment or return to work rates, or the timing of return to work decisions. ${ }^{6}$ We believe these are likely to be outstanding holiday leave or employer-funded parental leave payments, rather than a return to work following a period of parental leave.

Table 1 describes the characteristics of the study population. In 92 percent of cases, episodes of PPL lasted three or four months, 7 percent lasted one or two months, and 1 percent lasted five or six months. This pattern is consistent with the 12-14 week entitlement period. Note that recipients can return to work within the entitlement period, but that payment ceases at that point.

\section{Analysis and Results}

This section describes the employment and earnings patterns of the study population in the 18 months before and after beginning parental leave. We defined the first month after the last month employed to be the start of the leave period. This means that all people in the study population were employed in the month immediately before the leave period starting. This is month $(-1)$ in Figure 1. Month (1) is the first month of leave, and no one is employed in this month by definition.

\section{Employment and Earnings}

Table 1 describes the characteristics and recent employment and earnings history of the study population. $^{7}$

Over 99 percent of recipients were female, and most were aged 20-39 years. As expected, employment rates in the 12 months preceding the start of leave were close to 100 percent; however, there was some drop off at 1012 months before leave began. Eighty-four percent were employed 24 months before beginning leave. Monthly earnings during the period before leave began varied considerably across the study population. The median monthly earnings during the 7-12 months before leave began was $\$ 3140$. The 5 th and 95th percentiles were $\$ 1180$ and $\$ 6720$, respectively.
Table 1: Characteristics of Paid Parental Leave Recipients - July 2002- June 2005

\begin{tabular}{|c|c|}
\hline Characteristic & Percent \\
\hline Female & 99.2 \\
\hline \multicolumn{2}{|l|}{ Age } \\
\hline $15-19$ years & 1.8 \\
\hline $20-24$ years & 11.1 \\
\hline $25-29$ years & 26.6 \\
\hline $30-34$ years & 38.4 \\
\hline $35-39$ years & 18.3 \\
\hline $40-44$ years & 3.5 \\
\hline $45+$ years & 0.2 \\
\hline \multicolumn{2}{|l|}{ Length of first PPL spell } \\
\hline 1 month & 2.5 \\
\hline 2 months & 4.1 \\
\hline 3 months & 34.9 \\
\hline 4 months & 57.4 \\
\hline 5 months & 1.1 \\
\hline \multicolumn{2}{|c|}{ Number of PPL spells during the three-year study period } \\
\hline  & 95.9 \\
\hline 2 & 4.1 \\
\hline 3 & 0.0 \\
\hline \multicolumn{2}{|c|}{$\begin{array}{l}\text { Gap between receiving earnings from employment } \\
\text { and PPL }\end{array}$} \\
\hline no gap & 93.2 \\
\hline 1 month & 4.8 \\
\hline 2 months & 1.2 \\
\hline 3 months & 0.5 \\
\hline 4-5 months & 0.3 \\
\hline $6-11$ months & 0.1 \\
\hline \multicolumn{2}{|l|}{ Employed before taking leave } \\
\hline 1 month before & 100.0 \\
\hline 2 months before & 99.4 \\
\hline 3 months before & 99.4 \\
\hline 6 months before & 99.2 \\
\hline 9 months before & 98.8 \\
\hline 12 months before & 97.6 \\
\hline 18 months before & 89.6 \\
\hline 24 months before & 83.8 \\
\hline \multicolumn{2}{|l|}{$\begin{array}{l}\text { Average monthly earnings (conditional on } \\
\text { employment) before taking leave }\end{array}$} \\
\hline 3 months before & 3,500 \\
\hline 6 months before & 3,470 \\
\hline 12 months before & 3,450 \\
\hline 18 months before & 3,350 \\
\hline 24 months before & 3,290 \\
\hline \multicolumn{2}{|c|}{$\begin{array}{l}\text { Distribution of average monthly earnings } \\
\text { (conditional on employment) } 7-12 \text { months before } \\
\text { taking leave }\end{array}$} \\
\hline 95th percentile & 6,720 \\
\hline 75th percentile & 4.230 \\
\hline 50th percentile & 3,140 \\
\hline 25 th percentile & 2,250 \\
\hline 5th percentile & 1,180 \\
\hline Number of people in the study population & 49,150 \\
\hline
\end{tabular}

Figure 1 shows the percentage of the study population who were employed in the months before and after parental leave began. Depending on when PPL began, each person in the study population is observed for between 18 and 54 months afterwards. And so, outcomes after 18 months are based on a sub-sample of the total study population. Eighty-three percent of the study population are observed 24 months after beginning leave, and 50 percent are observed 36 months after beginning leave. 
Figure 1: Percent Employed, and Percent Receiving PPL, in the Months Before and After Starting PPL

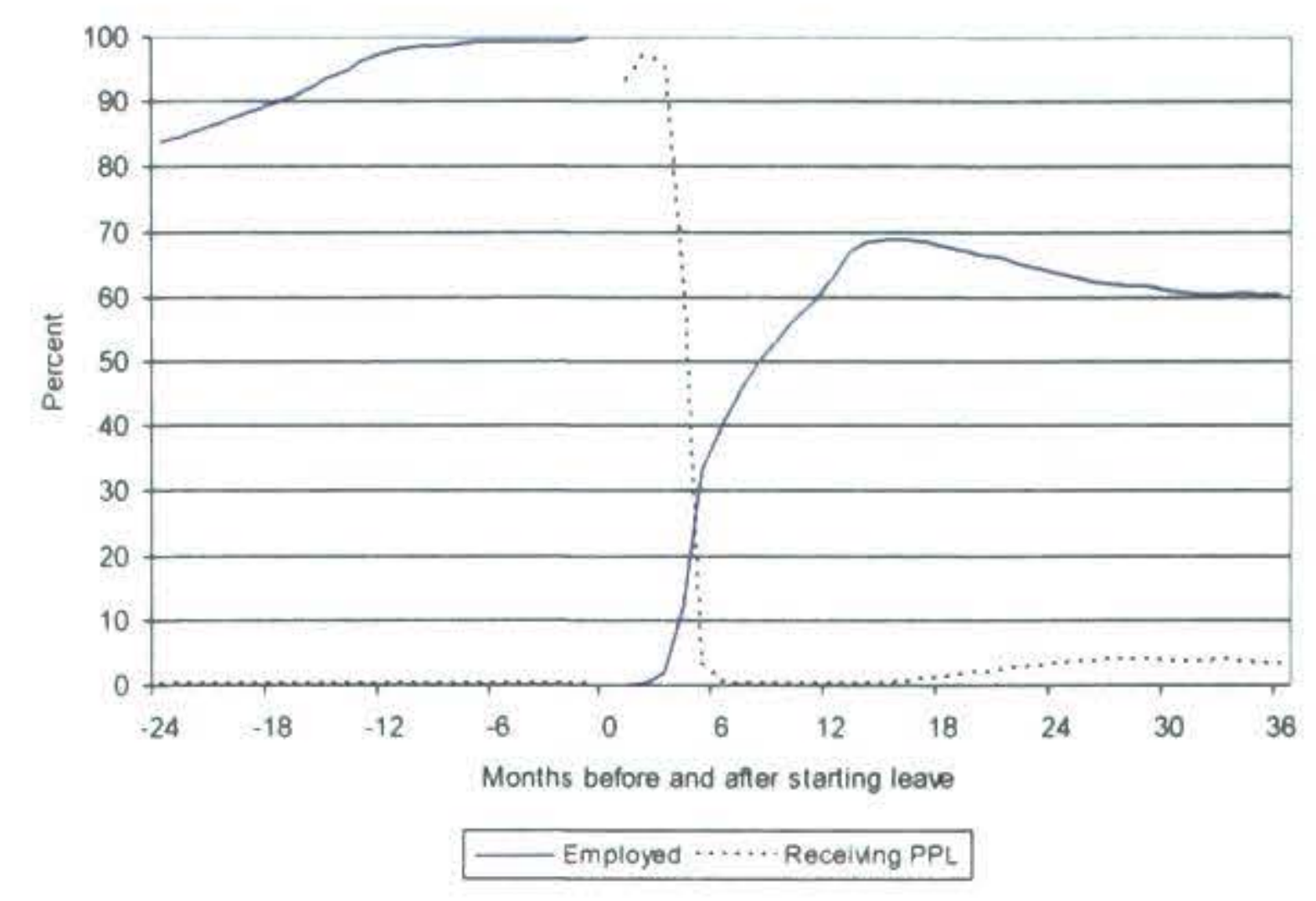

About 4 percent of the study population had a second episode of paid parental leave in the three-year study period, and 1 percent had a second episode within the 18-month follow-up period. Figure 1 reveals that second episodes of PPL started occurring 18 months after the first episode began. We adopted the approach of censoring outcomes at the start of a second PPL spell. Censoring only has a small impact, with virtually no impact on outcomes in the first 18 months. Some women who received PPL, and then went on to have another child would not be eligible for further PPL, either because they are not working, or because they do not meet the tenure and hours criteria.

Figure 2: Percent Employed with Earnings Above the Full-time, Full-month Minimum Wage Threshold in the Months Before and After Staring PPL

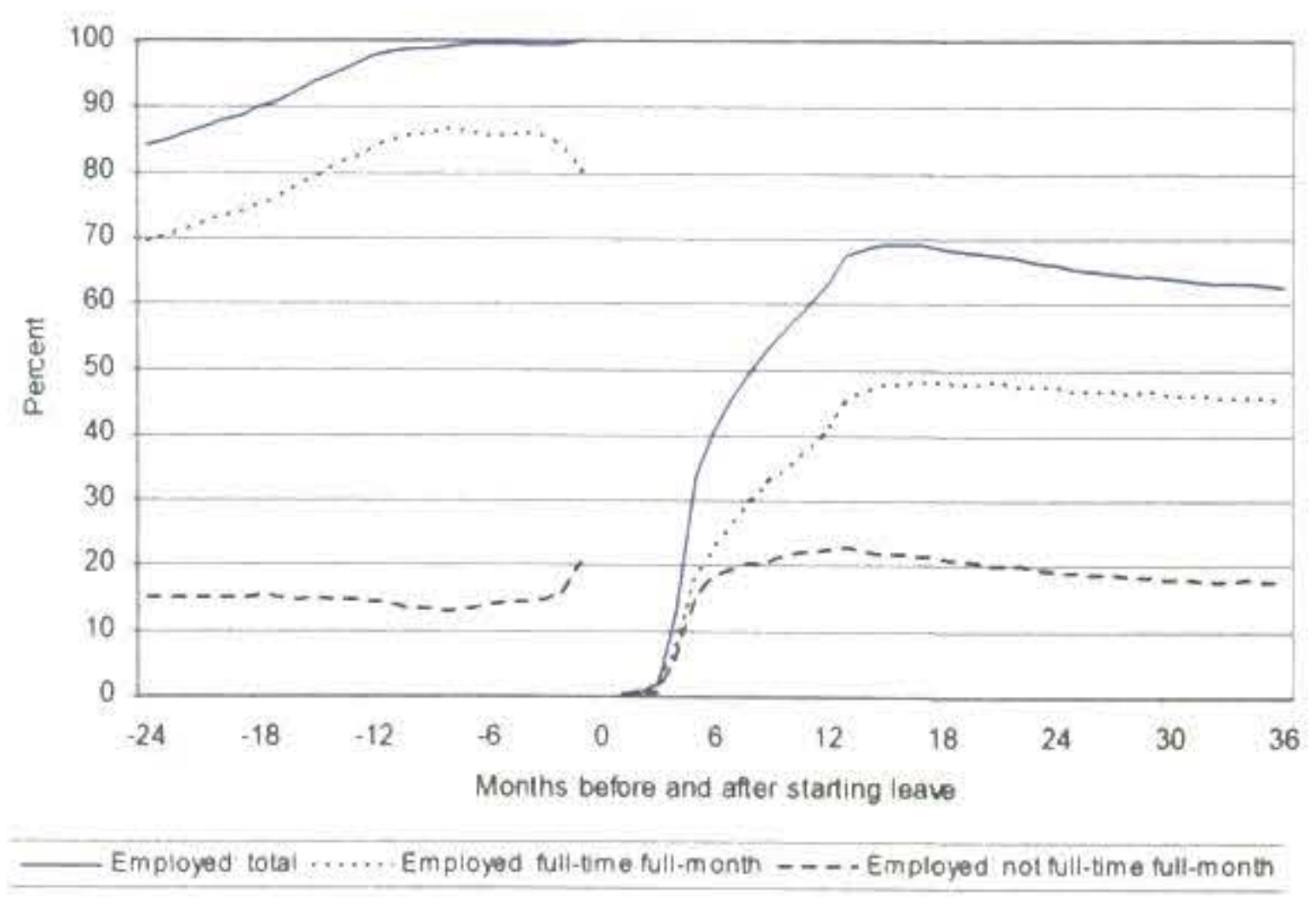

Table 2 describes the employment and earnings patterns of recipients during the 18 months after parental leave began. A small number of people return to work after taking only one month of leave, with 0.5 percent receiving some income from wages and salary in the second month. One-third of recipients were employed in month five, and 40 percent were employed in month six. The proportion working increases steadily, reaching 67 percent in month 13. Employment rates peaked at between 68 and 69 percent during months 14-18, before slowly declining to 62 percent 36 months later.

We consider a person to have returned to work within 12 months of beginning leave if they received earnings from employment at some stage during months $1-13$, and to have returned to work within six months of beginning leave if they received earnings from employment at some stage during months 1-7. A key finding is that 49 percent of recipients returned to work within six months of beginning leave, and 76 percent had returned to work within 12 months of beginning leave. Of those who returned to work within 12 months of beginning leave, 45 percent returned after taking three or four months leave, and a further 20 percent returned after five or six months. In total, nearly two-thirds of those who returned to work within 12 months had returned within six months of beginning leave. However a significant minority of those who returned to work did not remain employed for long. Three-quarters of those who returned to work within 12 months of beginning leave were employed in all of the following six months. Seventeen percent were employed for three to five months, and the remaining 6 percent were employed for only one or two out of the following six months.

\section{Change in Earnings}

Unfortunately LEED contains no information on hours worked. Previous research using LEED data has used the equivalent of the full-month full-time minimum wage that applied at the mid-point of the study period as a threshold below which employment is likely to be parttime or part-month. We adopted the same approach, and used monthly earnings below $\$ 1640$ (in March 2007 quarter dollars) as the threshold. We were particularly interested in knowing how much recipients reduced their hours of work following a period of parental leave, so we also compared individual's monthly earnings in the months before taking leave with their earnings afterwards. We identified the percentage of people earning less than 80,60 and 40 percent of their prior earnings.

Figure 2 shows that about 15 percent of recipients earned below the full-month full-time minimum wage threshold during the 12 month before taking leave. Of the 40 percent back at work six months after beginning leave, 45 percent were earning below the full-month full-time minimum wage threshold. The proportion decreased over time, with 36 percent of those working at 12 months, and 30 percent of those working at 18 months earning below the threshold. The absolute percentage employed and earning below the threshold was relatively constant at around 20 percent afterwards, even though it decreased as a percentage of total employment. 
Table 2: Employment and Earnings in the 18 months after starting Paid Parental Leave

\begin{tabular}{|c|c|}
\hline Characteristic & Percen \\
\hline \multicolumn{2}{|l|}{ Employed in the months after starting leave } \\
\hline 1 month & 0.0 \\
\hline 2 months & 0.5 \\
\hline 3 months & 1.7 \\
\hline 4 months & 12.5 \\
\hline 5 months & 33.3 \\
\hline 6 months & 40.1 \\
\hline 7 months & 45.3 \\
\hline 8 months & 49.8 \\
\hline 9 months & 53.2 \\
\hline 10 months & 56.6 \\
\hline 11 months & 59.3 \\
\hline 12 months & 62.7 \\
\hline 13 months & 67.3 \\
\hline 18 months & 68.4 \\
\hline 24 months & 65.8 \\
\hline $\begin{array}{l}\text { Percentage who returned to work within } \\
\text { months of starting leave }\end{array}$ & 76.0 \\
\hline \multicolumn{2}{|l|}{ Month returned to work after starting leave } \\
\hline 2 & 0.5 \\
\hline 3 & 1.3 \\
\hline 4 & 10.8 \\
\hline 5 & 21.7 \\
\hline 6 & 8.4 \\
\hline 7 & 6.6 \\
\hline 8 & 5.7 \\
\hline 9 & 46 \\
\hline 10 & 4.0 \\
\hline 11 & 3.7 \\
\hline 12 & 4.0 \\
\hline 13 & 4.8 \\
\hline Did not return to work within 13 months & 24.0 \\
\hline
\end{tabular}

For those who returned to work within 13 months of starting leave, the number of months employed in the 6 months afterwards

2

3

4

5

6

Percentage who returned to work within 13

months of starting leave

Returned to their previous employer only

Returned to their previous employer and started a new employment relationship within 13 months of Did not returned to their previous employer and started a new employment relationship within 13 months of starting leave

\section{Percentage who returned to work within 18 months of starting leave \\ Returned to their previous employer only \\ Returned to their previous employer and started a new employment relationship \\ Did not returned to their previous employer and \\ started a new employment relationship within 13 months of starting leave}

About 60 percent of those who worked at some stage during the 7-12 months after beginning leave earned less than before. Of the 70 percent who were working at some stage during the 7-12 months after beginning parental leave, 57 percent earned less than 80 percent of their previous average monthly earnings over the period, 43 percent earned less than 60 percent of there previous earnings, and 28 percent earned less than 40 percent of their previous earnings. Thirty-two percent were earning at a similar level to before, and 11 percent earned substantially more than before, with earnings which were 120 percent or more of their previous earnings.

About half of those who worked at some stage during the 13-18 months after beginning parental leave earned less than before. Of the 75 percent who were worked at some stage during the 13-18 months after beginning leave, 49 percent earned less than 80 percent of their previous average monthly earnings over the period. Thirty percent earned less than 60 percent of their previous earnings, and 21 percent earned less than 40 percent. Thirty-eight percent had a similar level of earnings, and 13 percent earned substantially more than before.

\section{Employment Relationships}

Next we examined whether recipients returned to their previous employer or not. Of the 76 percent who returned to work within 12 months, 49 percent returned to their previous employer, 15 percent did not return to their previous employer, but started a new employment relationship, and 12 percent returned to work for their previous employer and started a new employment relationship within 13 months of beginning leave. Of the 82 percent who returned to work within 18 months, 47 percent had returned to their previous employer, 17 percent did not return to their previous employer, but started a new employment relationship, and 17 percent returned to work for their previous employer and started a new employment relationship within 18 months of beginning leave.

\section{Prior Earnings}

We also examined whether there was any associations between earnings before taking leave and the likelihood of returning to work, experiencing a change in earnings after returning to work, or returning to the same employer.

We divided recipients into four groups (quartiles) on the basis of their average monthly earnings during the 7-12 months before beginning leave. The quartile groupings were: less than $\$ 2243$; between $\$ 2243$ and less than $\$ 3137$; between $\$ 3138$ and less than 4233 ; and $\$ 4233$ or more (in March 2007 quarter dollars.)

Figure 3 shows that employment rates were highest for those with the highest prior earnings, and lowest for those with the lowest prior earnings. The percentage working 3-6 months after beginning leave was the same across the four groups (with 40 percent employed again at six months), but diverged after that. Employment peaked at 78 percent in months 13-18 afterwards among those in the highest prior earnings quartile, compared with 60 percent among those in the lowest prior earning quartile. Employment rates begin to converge again after 18 months. 
Figure 3: Percent Employed in the Months Before and After Starting PPL, by Prior Earnings Quartile

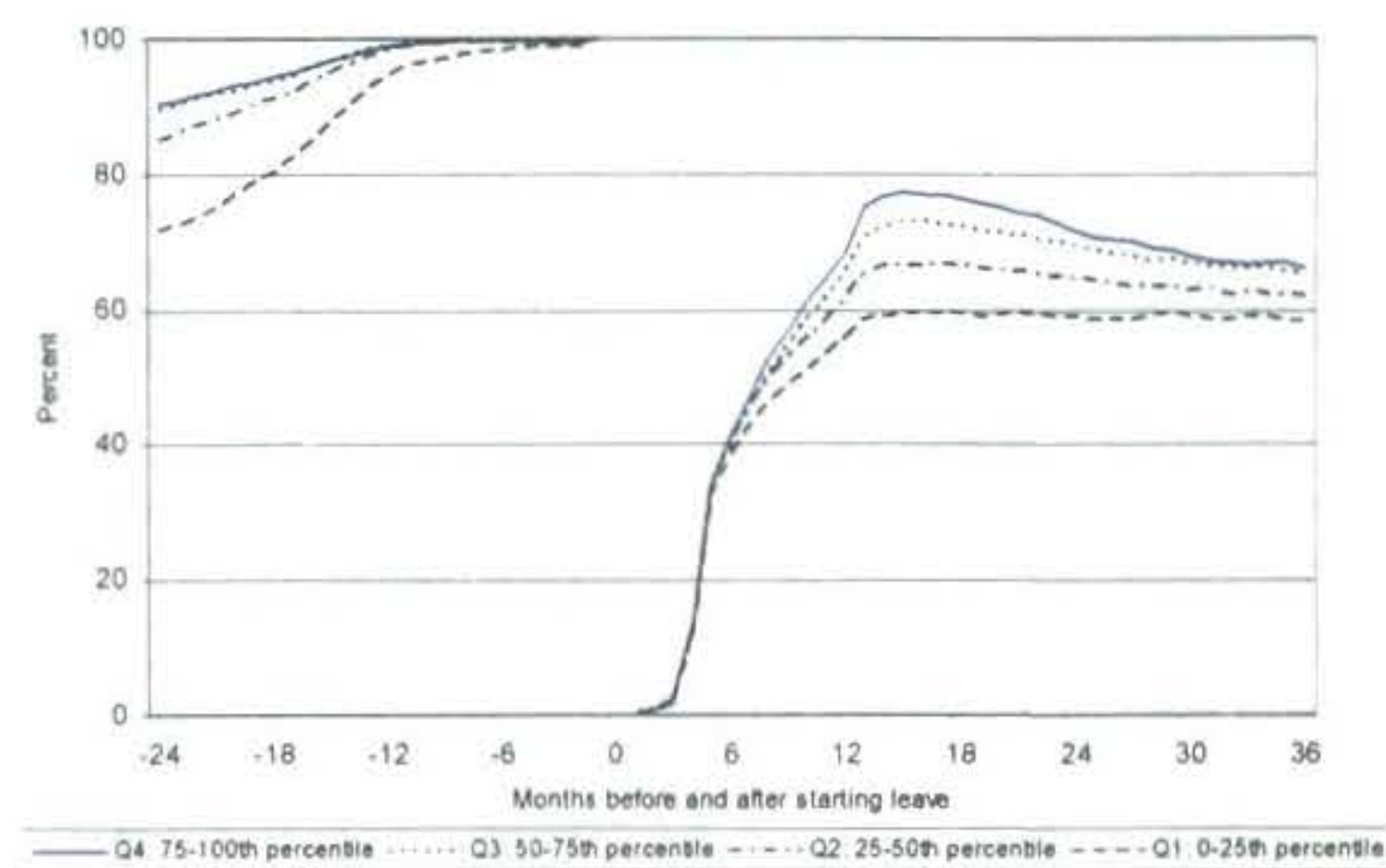

Those in the lowest quartile were the least likely to have returned to work within 12 months, and those in the highest quartile were the most likely to have returned to work. Sixty-nine percent of those in the lowest prior earnings quartile had returned to work within 12 months, compared with 83 percent of those in the lowest prior earnings quartile.

If they had been working at some stage during the 7-12 months after beginning leave, those in the lowest quartile were more likely to have experienced an increase in earnings, while those in the highest earning quartile were more likely have similar earnings to before.

In Table 3, recipients are again divided into four groups (quartiles) on the basis of their average monthly earnings during the 7-12 months before beginning leave. Changes in earning before and after taking leave are examined by looking at average monthly earnings during the 7-12 month period before beginning leave, and comparing this with earnings during the period 7-12 months afterwards. Percentage changes in average earnings were then grouped into five categories. Earnings were considered similar or unchanged if they were between 80 and 120 percent of prior earnings. Earnings were considered to have decreased if they were less than 80 percent of prior earnings, and to have decreased considerably if they were less than 40 percent of prior earnings.

Among those in the lowest prior earnings quartile, 11 percent earned more than before, 18 percent had similar earnings, 35 percent earned less than before, and 17 percent earned substantially less. Thirty-six percent were not working at all during the 7-12 months following the start of the parental leave period. Among those in the highest prior earnings quartile, 7 percent earned more than before, 25 percent had similar earnings, 44 percent earned less, and 21 percent earned substantially less than before. Twenty-four percent were not working at all during the 7-12 months following the start of the parental leave period.
Table 4 examines changes in earnings before and after taking leave by looking at average monthly earnings during the 7-12 month period before beginning leave, and comparing this with earnings during the period 1318 months afterwards. Among those in the lowest prior earnings quartile, 15 percent earned more than before, 21 percent had similar earnings, 33 percent earned less than before, and 14 percent earned considerably less. Thirtyone percent were not working at all during the 13-18 months following the start of the parental leave period.

Among those in the highest prior earnings quartile, 8 percent earned more than before, 36 percent had similar earnings, 40 percent earned less than before, with 15 percent earned substantially less. Seventeen percent were not working at all during the 13-18 months following the start of the parental leave period. If they had been working at some stage during months 13-18 after beginning leave, those in the lowest quartile were more likely to have experienced an increase in earnings, while those in the highest earning quartile were likely to have similar earnings to before.

Those with the highest prior earnings were also slightly more likely to return and stay with their previous employer than to have started a new employment relationship within 18 months of beginning leave.

\section{Change in Employment Relationship and Reduction in Earnings}

Those who did not return to the same employer, but started a new employment relationship were more likely to have reduced their earnings, than those who returned to the same employer.

Among those who returned to work for the same employer, 37 percent had similar average monthly earnings 7-12 months after beginning leave ${ }^{8}, 52$ percent earned less than before, and 23 percent earned considerably less. In comparison, among those who did not return to their previous employer, but started a new employment relationship, 20 percent had similar earnings to before, 72 percent earned less, and 45 percent earned considerably less than before.

Among those who returned to work for the same employer, 44 percent had similar average monthly earnings during the 13-18 months after beginning leave, 42 percent earned less than before, and 15 percent earned considerably less than before. In comparison, among those who did not return to their previous employer, but started a new employment relationship, 26 percent had similar earnings to before, 65 percent earned less than before, and 37 percent earned considerably less. 
Table 3: Average Monthly Earning in the Months 7-12 After Starting Leave as a Percentage of Average Monthly Earnings in the Months 7-12 Before Starting Leave

\begin{tabular}{|c|c|c|c|c|c|}
\hline \multirow{2}{*}{$\begin{array}{l}\text { Average earnings as a } \\
\text { percentage of prior } \\
\text { average earnings }\end{array}$} & \multicolumn{4}{|c|}{ Prior Earnings: Quartile } & \multirow[b]{2}{*}{ Total } \\
\hline & Q1: Lowest & Q2 & Q3 & Q4: Highest & \\
\hline $120 \%$ or more & 11.0 & 6.5 & 6.1 & 6.5 & 7.5 \\
\hline $80 \%$ and less than $120 \%$ & 17.5 & 22.8 & 24.7 & 25.4 & 22.6 \\
\hline $60 \%$ and less than $80 \%$ & 8.9 & 9.2 & 9.8 & 11.4 & 9.8 \\
\hline $40 \%$ and less than $60 \%$ & 9.2 & 9.3 & 10.5 & 11.7 & 10.2 \\
\hline Less than $40 \%$ & 17.1 & 20.3 & 21.4 & 20.9 & 19.9 \\
\hline No earnings & 36.3 & 31.9 & 27.5 & 24.2 & 30.0 \\
\hline Total & 100 & 100 & 100 & 100 & 100 \\
\hline
\end{tabular}

Table 4: Average Monthly Earning in the Months 13-18 After Starting Leave as a Percentage of Average Monthly Earnings in the Months 7-12 Before Starting Leave

\begin{tabular}{|c|c|c|c|c|c|}
\hline \multirow{2}{*}{$\begin{array}{l}\text { Average earnings as a } \\
\text { percentage of prior } \\
\text { average earnings }\end{array}$} & \multicolumn{4}{|c|}{ Prior Earnings: Quartile } & \multirow[b]{2}{*}{ Total } \\
\hline & Q1: Lowest & Q2 & Q3 & Q4: Highest & \\
\hline $120 \%$ or more & 15.2 & 9.5 & 7.7 & 7.8 & 10.0 \\
\hline $80 \%$ and less than $120 \%$ & 20.8 & 28.0 & 33.0 & 35.5 & 29.3 \\
\hline $60 \%$ and less than $80 \%$ & 9.7 & 10.4 & 11.4 & 13.4 & 11.2 \\
\hline $40 \%$ and less than $60 \%$ & 9.2 & 9.6 & 10.6 & 12.0 & 10.3 \\
\hline Less than $40 \%$ & 14.3 & 17.5 & 17.1 & 14.8 & 15.9 \\
\hline No earnings & 30.9 & 25.1 & 20.2 & 16.6 & 23.2 \\
\hline Total & 100 & 100 & 100 & 100 & 100 \\
\hline
\end{tabular}

\section{Discussion}

Our results confirm many of the findings from the Department of Labour's evaluation of PPL undertaken in 2005 , which estimated that about 80 percent of recipients had returned to work at some stage during the 14-17 months after beginning leave. The evaluation also found that many mothers reduced their hours, with around twothirds working part-time compared to one-third before the birth. While there is no information on hours worked in LEED, we observed that 43 percent of those who worked at some stage during the 7-12 months after beginning leave earned considerably less than before, and of those working during the 13-18 months after beginning leave, 34 percent earned considerably less than before. We found that about 80 percent of those who returned to work within 12 months went back to the same employer (initially at least), while the evaluation found only two-thirds went back to their previous employer.

\section{Conclusion}

This paper uses longitudinal data from the Linked Employer-Employee Dataset to describe the employment and earnings patterns of people who first received paid parental leave between 1 July 2002 and 30 June 2005.

Forty percent of recipients were working six months after beginning parental leave, 50 percent were working eight months later, and nearly 70 percent were working 12-18 months later. Overall 76 percent of recipients returned to work within 12 months of starting parental leave. Of those who returned to work within 12 months, two-thirds returned after taking six months leave or less. Most recipients continued working, with three-quarters employed continuously over the next six months.

Many people who returned to worked reduced their earnings quite considerably. There is no information on hours worked in LEED, so we compared average monthly earnings before and after taking leave. The majority of people who worked at some stage during the 7-12 months after beginning leave earned less than before; 57 percent earned less than 80 percent of their previous average monthly earnings over the period, 43 percent earned less than 60 percent of their previous earnings, and 28 percent earned less than 40 percent of their previous earnings. Thirty-two percent were earning at a similar level to before. During the 13-18 months after beginning leave, 34 percent earned less than 60 percent of their previous earnings and 21 percent earned less than 40 percent of their previous earnings. Thirtyeight percent had similar earnings to before.

Most people who returned to worked within 12 months of beginning leave returned to the same employer, while 19 percent started a new employment relationship. Fifteen percent initially returned to the same employer, and started a new employment relationship within 12 months of beginning leave. Thus, about one-third of those who returned to work started a new employment 
relationship within 12 months of beginning leave. Those who were working during the 7-12 months period after beginning leave, and who did not return to their previous employer were much more likely to have reduced their earnings, with 45 percent earning substantially less than before (less than 40 percent of their prior earnings). In comparison, only 23 percent of those who returned and stayed with their previous employer earned substantially less than before over the same period.

Employment and return to work rates were higher for those who had earned the most before starting parental leave. While employment rates were initially very similar, they diverged after six months. Overall, 83 percent and 69 percent of those in the highest and lowest prior earnings quartiles were back at work within 12 months. During months 13-18 after beginning leave, 78 percent of those in the highest earnings quartile were employed, compared with 60 percent among the lowest prior earnings quartile.

This research highlights the considerable variation in both the nature and timing of return to work decisions of recipients. Many recipients return to work relatively quickly, and, of the three-quarters who returned to work within 12 months, two-thirds returned after taking six months leave or less. While the majority of recipients who returned to work changed their working arrangements, most commonly by reducing their earnings, or in some cases starting a new job, around one-fifth were working for the same employer and had similar earnings $12-18$ months after starting leave.

\section{Notes}

1. This paper is an abridged version of LEED research paper published by Statistics New Zealand in December 2008.

2. Eligibility requirements for employees are intended to strike a balance between an employee's interest in job-protected leave from employment and the interests of employers who are required to keep an employee's job open while they are on leave.

3. The evaluation estimated that 75 percent of women had worked at some stage during the six months immediately before the birth, and that around 80 percent were eligible for PPL. Of those eligible, 83 percent took PPL.

4. See Kelly (2003) for a more detailed discussion of the LEED data.

5. Employee IRD number is missing for around 1 percent of records in LEED and this leads to some PPL recipients appearing to have no recent employment.
6. We only exclude single-month employment spells with the same employer.

7. In this study, we only consider wage and salary employment and not whether recipients returned to, or become self-employed after a period of paidparental leave. During our study period, paid parental leave was only available to employees earning wages and salary, who meet specific tenure and hours requirements. In July 2006, PPL was extended to include those who were selfemployed.

8. As previously, changes in earning before and after taking leave was examined by looking at average monthly earnings during the 7-12 month period before beginning leave, and comparing this with earnings during the periods 7-12 months and 1318 months afterwards. Earnings were considered similar or unchanged if they were between 80 and 120 percent of prior earnings, to have decreased if they were less than 80 percent of prior earnings, and to have decreased considerably if they were less than 40 percent of prior earnings.

\section{References}

Department of Labour (2007). Parental Leave in New Zealand - 2005/2006 Evaluation. Department of Labour.

Crichton, S. (2008). Work Patterns after Paid Parental Leave. Statistics New Zealand.

\section{Author}

Sarah Crichton

Senior Researcher

Work Directions

Department of Labour

PO Box 3705

Wellington

Sarah.Crichton@dol.govt.nz 